\title{
Research of the Application of Chinese Character Culture on Chinese
}

\section{Foreign Teaching}

\author{
Hongmei Zhu ${ }^{1}$ \\ ${ }^{1}$ Xi'an Fanyi University, Xi'an, Shaanxi, 710105
}

KEYWORDS: Character Culture; Foreign Teaching; Language Teaching; Application Research

\begin{abstract}
Influenced by becoming "second world economy", the global Chinese language continues to heat up constantly, more and more foreign students come to China for studying Chinese, Chinese and foreign new areas related professions, as well as Chinese School of relevant learning institutions . In China, as a foreign language teaching of a second language, the Chinese is an important stage to spread and promote Chinese culture, but also has influence appeal to enhance China's international status. Characters themselves as the language of communication, with a strong expressive image, in-depth image of the inside bears historic extremely rich Chinese culture, its independent cultural features have strong appeal in the foreign language teaching, the dissemination of Chinese culture best media charm. In foreign teaching Chinese, Chinese culture is not only reflected in the application of the internal culture, as well as its representation structure "shape, sound and meaning" more interesting, as well as a wide range of national social and cultural sense.
\end{abstract}

\section{Introduction}

Character representation structure is an important symbol of Chinese culture bearer, and as the language itself, its unique Latin Pinyin system does not have the word independence. For foreign students, the Latin alphabet is easy to learn, but to grasp the unique character writing and spelling charm on the pitch are difficult to grasp, for foreign students learning Chinese has brought some problems. Therefore, foreign teaching Chinese characters have on the cultural aspects of the application which is the main content of the paper to be discussed.

\section{Application of Chinese Character Culture}

Chinese characters culture is mainly reflected in its genus from the source text, carrying thousands of Chinese civilization, history and culture. Ancient Egyptian hieroglyphs, Chinese Oracle Mesopotamia and ancient Sumerian cuneiform is the world's oldest writing. Character mode combines the thinking of the Chinese nation, values and behavior of living and production methods have a strong flavor distinct cultural identity, history and culture of precipitation is Han Chinese for thousands of years, but also the carrier, having inherited the role of inheritance. In foreign teaching Chinese, the characters should be combined with culture, culture is Chinese characters kanji deep meaning inherent in the actual teaching, from the inside to the outside thorough way is to improve foreign students deepen their understanding of the important ways of Chinese characters. Foreign students to accurately understand and master the knowledge of Chinese characters must be drawn from the internal culture, expand the depth of Chinese learning. Culture is an important part of Chinese characters, which the master of Chinese culture can improve the level of knowledge. Enter 
the appropriate culture, favorable culture permeates the actual foreign language teaching in order to deepen the understanding of foreign students' understanding of Chinese characters. For instance, in a patriarchal society cultures, "M" and the word "women" contains the word culture: "M" word "field" refers to the vertical, orderly land, of which "force" the word refers to the arm force meaning, the word together on behalf of hard work in the fields of men; "women" in the word "female" refers to the female characters, where "Ji" means broom, the word refers to group together at home doing housework sweep with a broom woman, that became the home of a woman - woman at home doing housework, twenty years as "women." Use in the actual teaching special culture of Chinese characters, meaning implanted in the solution like small talk, said the same culture related to understanding learning Chinese characters, can effectively improve the awareness of foreign students.

\section{Structure Application of Chinese Characters}

Foreign Characters in Chinese teaching mainly for foreigners to modern Chinese characters for the content, the way of teaching a foreign language to master Chinese characters using the knowledge of teaching skills. Chinese Foreign purpose of teaching is clear interpretation of the modern form of Chinese characters, sound and meaning, enabling foreigners to learn to master Chinese writing and presentation skills. With China's rising international influence, Chinese is becoming the most important one of the most widely used language. Usually foreign teaching Chinese, mainly teaching Chinese characters by the application form, sound and meaning.

Teaching "shape" the application of Chinese characters, the structure of Chinese characters is split open to interpretation in teaching Chinese characters. Usually Chinese characters without radical words, but also without the word radical, which is a higher proportion of all the characters in modern times, so the use of split radicals can help foreign students of modern Chinese characters forming the word a preliminary understanding. As a noun class of birds, chickens, ducks, geese, magpie, cuckoo, swan, and the name of body parts, brain, legs, arms, liver, lung, spleen, both to make a scientific classification, while summarizing the interpretation in teaching teachers need detailed explanation of the law constitute clear characters, it can achieve the effect of teaching. There is a class of adjectives, such as fat, fat, swelling, swelling words. Of course there will be the Chinese character "shape" the situation is similar, such as the next single off "Ren" and double "left foot", which confusingly similar shape, especially in teaching described two radical "form" of the law can easy to remember. Constituting the word Ren's usually, you, he, partner, with which the law generally is about people, and constituting the word left foot in, usually line the street, $\mathrm{Xu}$, irresolute, irresolute, the law generally and road, walking about. Learn to recognize Chinese characters to master the law constitutes "form" can greatly improve the foreign students on the basis of a preliminary understanding of the Chinese language in teaching, for some relatively complex characters consisting of avoiding deeper explanation brings learning difficulty factor, in order to have a memory regular constituent words as the main teaching content, thereby increasing the efficiency of learning progress.

Teaching Chinese character "sound" application is the use of Chinese pinyin pronunciation for Chinese Teaching. Pronunciation of Chinese characters have certain rules, phonetic similarities is a major part of the pronunciation of Chinese characters. Pronunciation teaching is the use of next pronunciation of Chinese characters for identification, next to the delicate relationship between the word and its sound textures of Phonogram and associated with both common set of word formation before teaching Chinese language learning awareness. For example: microphone, fans, Mi, secret, these words have in common besides the sound of the word "rice", but the tone is different; Another 
example: Fang, housing, visit, put together the sound of these words next to the word " party "in the teaching of the" party "for the main course content can be extended at the same time the Israeli side more word sound next to the word phonetic characters for foreign students is very effective, and to some extent Latin alphabet spelling foreign students can also facilitate the pronunciation of Chinese characters memory. For starters, this mainly with phonetic pronunciation of learning, we can to some extent think learning Chinese is very difficult to eliminate the ill feelings, prompting faster into the learning state, learning in the fastest time to master beginner characters. Of course, the word next to the current law did not sound all scientific statistical norms included in the actual foreign teaching, students entering avoid misunderstanding, only to the common form of sound words were teaching at the primary stage.

In teaching "justice" applied Chinese characters, one of the "justice" also refers to the meaning, is the use of the word next to the shape of the original intent of the main characters to express their interpretation of the constitution, meaning. There are a large number of Chinese characters in modern word by word is formed next to the word constituted, having obvious rule, there is a certain sense of association with the shape next to the word. For example: river, river, lake, pond, are related to drops of - "Rui" related to its meaning in these terms contain water; Another example: lift, pinch, pull, shake, and have next to handle - "Rolling" relevant, which means these verbs apply to the "hand" of the action, as well as respiratory, suck, call, call, and other verbs have applied to the "mouth" of the movement, these words have shaped side independent meaning, significance. In foreign teaching, these functions use pictograms to the "India into the eye," the way to pass Chinese characters meaning, meaning, can effectively improve the memory of student learning Chinese characters. Different forms of the word next to the different pronunciation of the word, meaning different characters have different rules, in the actual teaching, teachers should be familiar with common shape, sound and meaning of words through the correct interpretation to explain, in order to ensure the accuracy of Chinese foreign students learning to master.

\section{The Understanding of the Difficult Learning of Foreign Students}

Modern Chinese generic characters larger number, average strokes per word had ten paintings, 30 kinds character strokes, strokes and strokes can constitute an independent radicals, radicals of up to more than five hundred different radical also form a different structure and a character. Chinese characters written on foreign students is generally considered the most prominent of the biggest difficulties point to the international English, the English word by the English word 26 letters composed on the writing far more than thirty and five strokes Character to more than one hundred kinds of radicals consisting of more simple. In many foreign students have the impression that Chinese people in what way to write these memories and Founder rectangular text. Some foreigners are curiosity hieroglyphics, the text always feel like some beautiful paintings, some of the characters and some lines even interested in him, to show some of the things of faith. Due to the complexity of the structural characteristics of Chinese characters, foreign students usually difficult to distinguish. Text itself is a symbolic sign language, its meaning is bound with its own social environment has some connection. Since foreign students grew up in a foreign language environment, did not experience a large number of Chinese language information activities and exposure to Chinese social environment, it is difficult to appreciate the meaning of the Chinese language and Chinese Information Society associated. Chinese in social activities, and social characteristics of the Chinese language has a convention-type connected social activity is linked whole history, culture and other integrated media. This range of media time and space are carrying large, often in direct statements would be too abstract, and that China's concept of inclusive 
philosophy of life also has some connection. Speech With simplified Chinese characters has prompted some sense also changing, many abstract concepts cannot be directly used specific words to explain this hazy sense for foreign students caused some problems. In addition, the difference psychologically different cultures of East and West brought also troubled one. Chinese thinking is relatively subtle, but Western thinking is relatively honest. Chinese people pay attention to spatial scale, as we often tend to be larger more spacious building door; Westerners value the time scale, such as Big Ben, the West point on the timeline pay special attention to. This difference is also reflected in the different: Chinese people are used to the size of the pecking order, and the West are accustomed to large gatherings, such as writing in China is Address - provincial, municipal, district, road, and the West and vice versa.

\section{The Meaning of Character Culture of Chinese Foreign Teaching}

Character Culture Teaching Chinese as a Foreign Language is not only as a way of teaching, but also an important way to promote the dissemination of Chinese culture. By way of teaching, to carry forward the Chinese culture and civilization thousands of great vision has important significance for the future development of the peaceful coexistence of the human world to build a bridge. Chinese Character Culture in Teaching Chinese as its unique characteristics "shape", "sound", "justice" is not only difficult point of language learning, teaching plus a reasonable right to learn will be able to digest association between the three, will be able to get vivid interest in learning form, for Chinese mastered it all downhill. Character culture is China's major carrier of culture of the Chinese nation for thousands of years of history precipitated image, in-depth study in order to understand which cultural knowledge and cultural meaning. In foreign teaching Chinese, Chinese culture the deep cultural connotation also improve learners' literacy and moral, but also to demonstrate the virtues of our cultural tradition for thousands of years in the subtle process in favor of Eastern and Western culture continues integration, and constantly strengthen the influence of China on soft power, to promote China's future to communicate with the world more rich layers and depth.

\section{Acknowledgements}

Project: Shaanxi Provincial Department of Education in 2015 Special Research Projects, Chinese Culture in the International Education Research.

Project Number: 15JK2044

\section{REFERENCE:}

[1] Yao Min. Motivation modern Chinese characters used in the Chinese Foreign Teaching [J]. Language Teaching and Research, 2011,02: 29-35.

[2] Jiao Dongmei. Cultural Characteristics of Chinese characters and foreign language teaching [J]. Heilongjiang College of Education, 2014,06: 70-73.

[3] Zhao Yanmei, Wang Aiping. Chinese Characters Teaching Strategies of the Cultural Implications of Chinese characters [J]. Education Forum, 2014,25: 159-160.

[4] Li Li. Character Culture Chinese Characters Teaching [J]. Gansu Radio \& TV University, 2009,02: 81-82 + 85 . 